\title{
SELF DIALÓGICO: TEORIA E PESQUISA ${ }^{1}$
}

\author{
Maickel Andrade dos Santos \\ William Barbosa Gomes"
}

\begin{abstract}
RESUMO. A ideia de self dialógico baseia-se na distinção entre o eu (o que conhece) e o mim (o que é conhecido) de William James, e na novela polifônica de Mikhail Bakhtin. O self não é mais centralizado e unificado, mas descentralizado e múltiplo. A dialogicidade ocorre entre posições do self que podem ser internas (eu enquanto homem, eu enquanto filho, eu enquanto profissional, eu como membro de uma comunidade) e externas (meu pai, meus amigos, meus colegas). As vozes estão em constante conversação, algumas vezes em conflito. O presente artigo revisa as proposições teóricas e metodológicas da teoria do self dialógico: pensamento narrativo e neurocognição da consciência. Também analisa o instrumento largamente utilizado na pesquisa empírica: o Repertório de Posições Pessoais, usado para mapear as relações entre diferentes posições do self. Dois problemas centrais permanecem para debate e pesquisa: como captar o self em diálogo e como explicar a possibilidade ou não de uma metaposição.
\end{abstract}

Palavras-chave: Self dialógico; psicoterapia; narrativa.

\section{DIALOGICAL SELF: THEORY AND RESEARCH}

\begin{abstract}
The idea of a dialogical self is based on the distinction between I (the one who knows) and me (what is known) of William James, and on the polyphonic novel of Mikhail Bakhtin. The self is no more centralized and unified, but decentralized and multiple. Dialogicity occurs among self positions that may be internal (I as a man, I as a son, I as a professional, I as a member of a community) and external (my father, my friends, my colleagues). The voices are in constant dialogue, sometimes in conflict. The present article reviews the theoretical and methodological propositions of the dialogica self theory: narrative thought and neurocognition of consciousness. It also analyzes the instrument largely utilized in empirical research: the Personal Position Repertoire, used for mapping the relations between different self positions. Two central issues remain for debate and research: how to observe the self in dialogue and explain the possibility or impossibility of a metaposition.
\end{abstract}

Key words: Dialogical self; psychotherapy; narrative.

\section{SELF DIALOGICO: TEORÍA Y INVESTIGACIÓN}

RESUMEN. La idea del self dialógico se basa en la distinción entre el yo (quién conoce) y el mí (lo que es conocido) de William James, y en la novela polifónica de Mikhail Bakhtin. El self no es más centralizado y unificado, pero descentralizado y múltiplo. La dialogicidad ocurre entre posiciones del self que pueden ser internas (yo cuando hombre, yo cuando hijo, yo cuando profesional, yo cómo miembro de una comunidad) y externas (mi padre, mis amigos, mis compañeros). Las voces están en constante conversación, algunas veces en conflicto. El presente artículo revisa las proposiciones teóricas y metodológicas de la teoría del self dialógico: pensamiento narrativo, y neurocognición de la consciencia. También analiza el instrumento largamente utilizado en la investigación empírica: el Repertorio de Posiciones Personales, utilizado para mapear las relaciones entre diferentes posiciones del self. Dos problemas centrales permanecen para debate e investigación: cómo captar el self en diálogo y cómo explicar la posibilidad o no de una meta posición.

Palabras-clave: Self dialógico; psicoterapia; narrativa.

Conceitos de self são largamente utilizados na prática psicológica. Historicamente, esses conceitos compartilham algumas características comuns quanto à concepção do self, como a de um self centralizado, a

\footnotetext{
Apoio: CNPq.

Psicólogo. Mestre em Psicologia do Desenvolvimento.

\# Psicólogo. Doutor em Higher Education. Professor do Programa de Pós-Graduação em Psicologia da Universidade Federal do Rio Grande do Sul.
} 
de um self estrutural e a de um self de difícil mudança. Recentemente, porém, houve uma mudança nesse padrão, com o surgimento da ideia de um self descentralizado, narrativo e em movimento, ou seja, em constante processo de mudança. Este artigo oferece uma visão breve, mas abrangente, das diversas proposições teóricas e metodológicas sobre o self dialógico. Discute, assim, a sustentação conceitual e empírica do construto da dialogicidade do self e levanta possibilidades para a investigação científica. $\mathrm{O}$ eixo da discussão reside nas noções de centralização e descentralização do self, um dos aspectos centrais do self dialógico.

\section{O SELF DIALÓGICO}

A teoria do self dialógico é a conjunção dos conceitos de self e de narrativa (Hermans, Kempen \& Van Loon, 1992), apoiada na teoria de self de William James (1890/2007) e na noção de novela polifônica de Mikhail Bakhtin (1963/1984). Provêm da teoria de James a distinção entre "eu" e "mim," e a ênfase na continuidade da experiência do self. Como se sabe, James dividiu o self em quatro partes: o self material, que abrange desde o corpo até as propriedades privadas de um indivíduo; o self social, que provém da imagem que outras pessoas têm deste indivíduo; o self espiritual, composto de suas faculdades psíquicas; e o ego puro, considerado o senso de "mesmidade", a partir do qual existe o senso de continuidade da experiência consciente. Enquanto as três primeiras partes do self constituem o "mim", que é conhecido, o ego puro constitui o "eu", que conhece. Assim, para James o self, como conhecimento que alguém tem de si mesmo, implica uma dualidade entre "eu" e "mim". James ressalta a dificuldade em estabelecer o que é "mim" e o que é "meu", apontando que algum objeto ou característica pode, em um dado momento, fazer parte de qualquer uma das duas classificações. $O$ conteúdo do self é flutuante, e em sua forma mais ampla, engloba tudo o que alguém poderia chamar de "meu".

Da novela polifônica de Bakhtin, proveniente dos estudos da obra literária de Fiódor Dostoyevsky (1821-1881), provém a noção da dialogicidade e das diferentes vozes. Em Bakhtin (1963/1984), cada personagem, com suas características conflitantes, traz uma voz independente. Personagens com suas vozes diferentes e simultâneas implicam na concepção de sua coexistência e na possibilidade do diálogo entre elas. Para Hermans (2003), Bakhtin dá ênfase à descontinuidade, diante da multiplicidade de vozes divergentes. Nesse novo contexto, a diferença entre relações lógicas e dialógicas é revisitada. O exemplo fornecido por Hermans para ilustrar a diferença é o de duas frases idênticas. A relação lógica entre elas seria de identidade, devido a serem iguais; já a relação dialógica seria de concordância. A razão para essa constatação é que, se levadas em consideração enquanto enunciados proferidos por pessoas em comunicação, as frases são diferentes, pois a primeira seria uma constatação e a segunda uma confirmação. Assim, relações dialógicas complementam o significado de relações lógicas.

O próprio Bakhtin (1963/1984), em seus estudos literários, traçou um paralelo entre os diálogos dos personagens de uma novela polifônica e o diálogo interno, que, segundo ele, seria fundante da própria personalidade. Além disso, o autor estudou o que chamou de "linguagens sociais", que representam na fala dos indivíduos a bagagem cultural da sociedade em que estão inseridos. Assim, ao conceber o diálogo interno culturalmente inserido em um cenário em que cada uma das vozes representa uma posição autoral distinta, Bakhtin forneceu subsídios para a concepção de uma teoria narrativa psicológica que entenda a história de um indivíduo por suas relações dialógicas.

Combinando as ideias de Bakhtin e Dostoyevsky, Hermans e colegas (1992) definiram o self dialógico como "uma multiplicidade dinâmica de posições do 'eu' relativamente autônomas em uma paisagem imaginária” (p. 28). O eu circula entre essas diversas posições, espacialmente situadas, e imaginativamente dota-as de voz, o que possibilita o diálogo entre elas. Cada voz, como um personagem, pode estabelecer narrativas sobre seu respectivo mim, e esse diálogo incessante e multifacetado constitui um self narrativamente estruturado e descentralizado (Hermans, 2001a).

$\mathrm{O}$ aspecto narrativo é de extrema importância, na concepção de Hermans e colegas (1992). As ideias que deram origem à abordagem narrativa provêm da crítica literária, na qual a formação de significados na vida cotidiana seguiria, de certo modo, o mesmo padrão da produção textual. Uma das consequências disso é a ênfase na capacidade imaginativa do self, pois apenas com a imaginação torna-se possível formar diferentes histórias para cada posição em que circula o "eu" (Hermans \& Kempen, 1998).

$\mathrm{Na}$ perspectiva dialógica, o self circula entre posições internas e externas. Por posições internas são entendidas aquelas que se referem às diferentes facetas de um indivíduo (por exemplo, o papel de pai), enquanto posições externas são aquelas referentes a pessoas de seu convívio social (por exemplo, um colega de trabalho). À primeira vista, essa 
diferenciação parece reeditar a oposição entre indivíduo e sociedade, apenas transposta ao self, porém dois argumentos contrariam essa ideia. $\mathrm{O}$ primeiro diz respeito à capacidade imaginativa. Um indivíduo pode dotar posições externas de vozes formadas quase totalmente por conteúdo imaginado, sem a necessidade de uma correspondência com a realidade. $\mathrm{O}$ segundo refere-se ao foco da teoria. $\mathrm{O}$ interesse não está na caracterização de posições, mas nas relações entre as posições (Gonçalves \& Salgado, 2001).

Diante de um self descentralizado, os autores preveem momentos transitórios de unidade, que não seria considerada propriedade a priori, e sim, um estado provisório. Destarte o self é um sistema cujo funcionamento visa à unidade, por meio das relações dialógicas entre suas posições, embora tal estado nunca seja atingido de forma mais duradoura. A transitoriedade das relações entre as posições segue alguns padrões, implicando na existência de hierarquia. Hermans (2001a) salienta que o diálogo entre as posições é pontuado por relações de poder e dominação, ocasionando a existência de hierarquias momentâneas. As relações entre as posições podem inclusive tornar-se estereotipadas, com a exclusão de algumas delas do diálogo, caso o eu não consiga circular entre elas.

O monitoramento de posições leva ao surgimento da metaposição. Segundo Hermans (2001b), em determinados momentos é possível o eu assumir uma posição com características especiais, que contribui mais do que as outras para a integração e unidade do repertório de posições do self. Entre as características dessa posição encontra-se a obtenção de certo distanciamento em comparação com o resto do repertório, que possibilita a inter-relação de posições como parte da história pessoal do indivíduo. A metaposição também permite o vislumbre da direção da mudança dentro do self, bem como a avaliação da importância das posições dentro de uma perspectiva teleológica. Há uma separação do fluxo de experiências, o que posiciona o indivíduo na condição de autor que se enxerga como ator nas diversas situações de vida. O desenvolvimento de uma metaposição ocorre por meio do treino, da psicoterapia e de outras formas de autorreflexão na vida diária.

A psicoterapia é o elo principal entre a teoria e a prática na teoria dialógica. $\mathrm{O}$ processo psicoterápico é concebido como uma reorganização do repertório de posições do self do paciente, visando a maior flexibilidade e movimentação do eu. A reorganização do repertório de posições pode ser facilitada pela inovação do self, pela construção de um espaço dialógico e pelo estabelecimento e fortalecimento de uma metaposição (Hermans, 2003).

A inovação do self consiste em três procedimentos. O primeiro deles é a introdução de uma nova posição no sistema, o que implica necessariamente uma reorganização do self. $\mathrm{O}$ segundo é a mudança na acessibilidade de uma posição no self, transformando as relações hierárquicas internas e dando a essa posição uma voz mais saliente. $\mathrm{O}$ terceiro procedimento é a formação de coalizões ou clusters entre posições, reforçando-se umas às outras e formando subsistemas que levam à inovação.

A construção de um espaço dialógico envolve o estabelecimento de uma relação entre psicoterapeuta e paciente que favoreça a reflexão mútua. Uma condição necessária para que isso ocorra é a existência de certo grau de simetria entre as duas partes, de modo a evitar que o profissional domine a conversa com suas ideias. Note-se que o psicoterapeuta se torna, por definição, uma nova posição externa que se apresenta ao self do paciente, por conseguinte passa a fazer o papel de metaposição, principalmente no início do processo.

Hermans (2002) propõe a metáfora "sociedade da mente" para descrever o funcionamento do self dialógico, argumentando que "não há diferença entre as posições que uma pessoa assume no self e as posições que os indivíduos assumem como parte de uma sociedade heterogênea" (p.147). Prosseguindo, ele afirma que "self e sociedade funcionam como uma polifonia de vozes consonantes e dissonantes" (p.148).

\section{RAMIFICAÇÕES E DESENVOLVIMENTOS DA TEORIA}

A teoria do self dialógico atraiu a atenção de psicoterapeutas preocupados com a questão da flexibilidade e a dialogicidade entre as vozes (Santos, 2007). Outros estudos destacaram as aproximações com a semiótica, tanto na perspectiva vygotskyana (Leiman, 2002) quanto no pragmatismo americano (DeSouza, 2005).

A semiótica traz dois pontos centrais para um entendimento crítico do self dialógico: a distinção entre self e identidade e a noção de mediação de signos na troca de posições no self. Leiman (2002) introduz o conceito de signo como a unidade entre uma forma material e um depósito de significado. A importância dos signos para o self dialógico, segundo o autor, está na noção de que o eu só realiza o movimento de troca de posições por meio deles. Em 
outras palavras, o movimento dialógico só ocorre pela mediação do signo na experiência.

DeSouza (2005), por sua vez, trouxe a distinção entre self e identidade proposta por Wiley (1994). Self é uma estrutura geradora de significados, constante, que atribui sentido ao mundo, organizando a experiência individual. Identidades, por outro lado, são significados gerados pelo self, surgidos mediante o contato social. Sua natureza é inerentemente provisória, uma identidade específica não é permanente nem imutável. Uma identidade pode tomar o lugar do self, embora, neste caso, a função geradora de significados seja prejudicada, gerando quadros psicopatológicos. Isso se daria porque todos os sentidos das outras identidades seriam interpretados pela dominante. Esta distinção, aplicada ao self dialógico, sugere que uma fixação do eu em alguma posição específica prejudicaria o movimento do self, que é a livre circulação do eu entre as posições. A função geradora de significado descrita por Wiley, no contexto do self dialógico, seria fluida, circulante, emergente das interações entre as posições, bem como caracterizada por seus produtos (os significados), e não por uma estrutura (pois não há um self estático).

A ideia de que o movimento do eu pelas diferentes posições, quando prejudicado de alguma maneira, possa levar à psicopatologia, é explorada por Lysaker e Lysaker (2002). No estudo da esquizofrenia, os autores propõem a conceitualização do distúrbio enquanto falha na hierarquia do self dialógico. Uma das possibilidades é a monologização do self, em que o movimento dialógico torna-se muito restrito. Outra possibilidade é a de que haja uma falta de hierarquia entre as posições do self, o que resultaria numa cacofonia de vozes. Em ambos os casos a capacidade adaptativa do self ficaria muito comprometida, não dando conta de uma ordenação eficaz da experiência. Lysaker e Hermans (2007) relatam um caso de psicoterapia com paciente esquizofrênico em que a referida cacofonia deu lugar a um diálogo interno variado, o que resultou em qualidade de vida e funcionamento adaptativo aprimorado.

Lewis (2002) examinou interfaces entre funções cerebrais e os conceitos de diálogo e de posições independentes do eu. Ele estava insatisfeito com as explicações oferecidas para a multiplicidade de posições do eu, pois o cérebro, como sistema, precisa estar voltado de maneira unificada para uma experiência consciente. Para contornar o problema, Lewis argumentou que grande parte dos diálogos internos são monólogos que ocorrem em nível sublingual. Assim, não haveria a necessidade de um foco da atenção, que existiria caso os diálogos fossem elaborados em palavras e frases. A ausência de um foco atencional possibilitaria a ocorrência paralela e simultânea dos monólogos, condição necessária para a concepção de posições do eu. Outras posições e a possibilidade de diálogo existiriam apenas enquanto expectativa, que direcionaria o processo sem que realmente houvesse outra parte envolvida. $\mathrm{O}$ aspecto imaginativo do self seria responsável por uma antecipação que resultaria em uma economia de tempo e recursos.

Para Lewis (2002), a solução apresentada, embora eficiente, não comportaria todas as manifestações de diálogo interno, sendo necessário algum tipo de complementação. Um exemplo seria o de situações em que uma pessoa realiza uma conversa interna, parcialmente consciente, tomando a si mesma como objeto e falando subjetivamente como outra pessoa. Nessa situação ocorreria uma rápida mudança na resposta cerebral para viabilizar a troca no foco da atenção. Tal troca seria possível desde que existissem dois sistemas que tivessem processamentos paralelos e competissem pela atenção. Para Lewis, o córtex orbitofrontal e o córtex cingulado anterior desempenhariam esse papel, tendo em vista que a atividade tem pouca ligação neuronal. A competição é orientada pela carga emocional das situações vividas. O córtex orbitofrontal é ativado por emoções negativas, em particular a ansiedade, enquanto o córtex anterior cingulado é ativado na realização de tarefas "frias", de caráter cognitivo.

A flexibilização do conceito de dialogicidade, levando em consideração aspectos inconscientes e não-verbais, foi considerada por Fogel, Koeyer, Bellagamba e Bell (2002). Para os autores, as crianças desenvolvem uma forma não verbal de self dialógico nos primeiros 18 meses de vida. $\mathrm{O}$ processo ocorreria mediante a utilização de padrões de diálogo semelhantes a roteiros vagos de interação, que, quando executados, envolvem a improvisação de acordo com o momento. Assim, existiriam tanto roteiros rígidos que quando utilizados sofrem pouca ou nenhuma modificação, tornando-se estereotipados - quanto roteiros criativos, que, quando acionados, trariam abertura e inovação, originando novas relações dialógicas.

Fogel et al (2002) afirmaram que a natureza das posições do eu refere-se, nos primeiros anos de vida, à corporificação da experiência. A criança experimentaria com os sentidos: tocando, vendo e levando objetos ou partes do corpo à boca. Essas experiências serviriam de conteúdo para as posições iniciais. Por exemplo, uma criança observando sua mão em movimento lidaria com duas experiências 
distintas: a sensação proveniente da mão, proprioceptiva e táctil; e a visão da mão, proveniente do aparato visual. Utilizando os padrões de diálogo, o bebê passaria a uma crescente integração destas experiências, coordenando movimentos e desenvolvendo uma imagem de si.

Fogel et al (2002) sugerem que o estudo do surgimento e desenvolvimento pré-verbal do self dialógico pode fornecer indícios de como estes elementos permanecem subjacentes às formas de diálogo verbal nos adultos. Também afirmam que os rumos e predisposições desse desenvolvimento inicial podem ser indicativos de diferenças individuais posteriores, incluindo psicopatologias, num retorno às teorias que creditam às experiências infantis um grande papel no desenvolvimento.

O desenvolvimento do self dialógico na infância e na adolescência foi investigado, respectivamente, por Branco (2005) e por Oliveira (2006). Branco estudou a metacomunicação na formação do self, em especial a metacomunicação relacional. Trata-se de uma elaboração sobre o aspecto social do desenvolvimento do self que vai ao encontro das concepções dialógicas. Oliveira (2006) destacou a formação da identidade em adolescentes, indicando esse período do desenvolvimento como privilegiado para a formação de novas posições do self. Especificamente, a expansão do mundo social de indivíduos nessa faixa etária forneceria o material necessário para que se operassem mudanças no self.

Com ênfase no desenvolvimento humano, Valsiner (2002) sugeriu um modelo de diálogo entre as posições do self, mas sem enfocar alguma faixa etária específica. Inicialmente, o self pode apresentar tanto o heterodiálogo, com pessoas reais ou imaginárias, quanto o autodiálogo, consigo mesmo. Para Valsiner, essas modalidades de diálogo ocorrem no que ele designa de cerne do self dialógico, o sistema Aqui-Agora-Eu, ou AAE. O AAE envolve a união dos aspectos temporais (agora), espaciais (aqui) e agenciais (eu). A partir de experiências passadas, esse sistema determina, dentro do campo do self dialógico, em que área a construção de sentido será aplicada em um dado momento. Assim, uma mediação semiótica restringe, dentro de um campo disponível, aquelas experiências passíveis de realização no self. $\mathrm{O}$ self alterna momentos sem hierarquia entre posições, que produzem uma polifonia de voz, com de momentos em que a diferenciação posterior entre elas resulta em uma crescente organização, caracterizandose como um sistema que se auto-organiza.

Uma das noções mais importantes introduzidas por Valsiner (2002) é a do self dialógico como autocatalisador. Em outras palavras, seus componentes (posições do eu) produzem a si mesmos enquanto lidam com o fluxo da experiência. Tomando emprestado um termo da Química, o autor afirmou que a produção de sentido no self ocorre a partir da combinação de elementos. Esses elementos, porém, não se combinam sem a ajuda de um catalisador, um terceiro elemento que serve para mediar o processo. Assim, o elemento A combina-se com o catalisador C, com o novo par combinando-se com $\mathrm{B}$ posteriormente. A e B combinam-se, e C então se desliga, deixando para trás um elemento novo. A presença ou ausência do catalisador, assim como sua natureza, termina por indicar quais elementos serão combinados. O resultado é o surgimento de novas posições no self, a partir de um processo de produção de sentido.

Prosseguindo a analogia com processos químicos, Valsiner (2002) chamou de síntese a produção de novas posições. O termo significa a junção de duas partes em um todo que é novo. As condições para a ocorrência da síntese encontram-se entre a polifonia e a monologicidade. $\mathrm{O}$ autor oferece uma tipologia das relações entre posições no self dialógico como uma tentativa de explicar o processo dos mecanismos de desenvolvimento. Dois tipos de relação estão ligados à estabilidade do self: o reforço mútuo, em que posições opostas atingem um equilíbrio dinâmico, e a polifonia, que resulta em proliferação e dispersão de posições. Ocorre então uma ilusão de complexidade, pois o grande número de posições acaba por não diferenciarse significativamente, resultando em ausência de estruturação.

A estabilidade é sempre seguida de um momento de instabilidade (Valsiner, 2002). Os tipos de relação decorrentes são os de expansão e os de apropriação. As relações de expansão subdividem-se nas de escalada mútua, em que cada posição de um par conflitante caminha para uma crescente generalização, mantendo a oposição intacta, e nas de desacoplamento, em que a relação é rompida e cada posição passa a surgir sem a outra. Ambas têm em comum o fato de que mantêm as posições como se encontravam antes, mas resultam em desenvolvimento. Já as relações de apropriação modificam algum de seus componentes. Elas subdividem-se em relações de dominação, em que uma posição é subordinada à outra, seu extremo, a expropriação, em que a posição subordinada é extinta, e de ventriloquismo, em que uma posição utiliza a outra para se expressar.

Valsiner (2002) afirma que o self dialógico pode ser comparado a um "solucionador de problemas preguiçoso" (p. 261), no sentido de que predomina 
uma multiplicidade de vozes levemente organizadas, e não uma busca constante pela síntese. $\mathrm{O}$ autor aponta que, para que se considere esse modelo como um modelo de desenvolvimento, o mais importante é levar em conta a flexibilidade adaptativa de generalizar apenas parte da experiência na produção de sentido. A capacidade de diferenciação da experiência (entre o que é e não é importante em um dado momento) tornase central nessa perspectiva, não apenas no entendimento, mas também na relação com o mundo. A emergência de novas posições decorre desse processo. A apreensão empírica das minúcias desse sistema é um desafio que motivou a realização de outros estudos e a construção de instrumentos.

\section{EVIDÊNCIAS EMPÍRICAS DA TEORIA DO SELF DIALÓGICO}

As evidências utilizadas para as primeiras construções teóricas acerca do self dialógico, descritas até agora, vieram principalmente da psicoterapia (Hermans, 2001b). Estudos de caso (Beebe, 2002; Fogel et al, 2002; Hermans, 2001b) e artigos teóricos predominaram até o início da década (Leiman, 2002; Valsiner, 2002). Os últimos anos, em contrapartida, têm sido caracterizados por uma maior variedade de instrumentos e metodologias.

Raggat (2000) desenvolveu o Personality Web, um instrumento que busca a identificação de vozes do self. O autor refere-se às vozes narrativas do self como sendo estruturas de avaliação moral. Cada voz estaria inerentemente posicionada dentro de uma moral da sociedade em que está inserida. Cada voz, necessariamente, representaria uma posição e uma ação moralmente avaliadas, o que levaria ao conflito intrapsíquico entre elas. Diferentes vozes representariam diferentes concepções do que seria uma vida correta ou uma vida feliz.

O instrumento de Raggat (2000) consiste em duas etapas. A primeira é o diálogo com a cultura, em que itens são obtidos refletindo a relação de um indivíduo com o mundo em diversas dimensões, como pessoas, objetos, partes do corpo e eventos de vida. A segunda envolve a síntese das vozes, em que as relações entre os itens são classificadas por meio de uma escala e representadas em um gráfico bidimensional. A proximidade espacial dos itens indica a caracterização de agrupamentos que são chamados de vozes narrativas. A representação gráfica, porém, não consegue dar conta da complexidade das relações. $\mathrm{O}$ resultado é que, em estruturas bidimensionais, ocorre uma simplificação e fragmentação dos resultados. Em última instância eles terminam por descaracterizar a tentativa de representação.

Hermans (2001b) propôs o Repertório de Posições Pessoais (RPP) como um procedimento aberto para o acesso ao self dialógico. O instrumento consiste em duas partes. A primeira delas é quantitativa e composta por uma lista de posições internas e externas do self relacionadas entre si, chamada, por isso, de Matriz de Posições Internas e Externas. Na lista de Posições Internas encontram-se: eu como homem, eu como marido, eu como pai, etc. Nas Posições Externas estão: minha esposa, meus filhos, meus colegas, etc. A segunda parte é tanto quantitativa quanto qualitativa e envolve a construção de valorações (frases ou pequenas histórias) às quais são relacionados afetos, a partir do ponto de vista de uma posição, escolhida pelo participante como a mais importante de seu repertório, a qual é chamada de Matriz de Valorações e Afetos. Os resultados, segundo Hermans, formam um quadro geral da estruturação do self dialógico naquele momento. Dentre os dois instrumentos criados, o RPP tem sido mais utilizado, seja no formato original seja com algumas modificações.

Uma dessas modificações, feita por Santos (2007), envolveu a gravação da fala em voz alta dos participantes (solicitados a expressar seus pensamentos de forma livre) enquanto respondiam ao instrumento. $\mathrm{O}$ objetivo da mudança foi obter dados empíricos complementares que mostrassem o self dialógico em movimento, em oposição a um retrato estático, mediante o exame das verbalizações em sequência. A análise desse registro verbal, feita de maneira contínua, sem interrupções ou recortes que não fossem os dos próprios participantes, colocou em evidência a dimensão temporal do self. A importância desse enfoque residiu na possibilidade de observar o caráter transitório da organização descentralizada do self, por meio da presença constante da alternância entre pontos de vista. Além disso, foi possível constatar que essas mudanças por vezes seguem padrões cognoscíveis, chamados de temas horizontais e verticais, que perpassam a circulação entre as diferentes posições.

Outro estudo recente (Stemplewska-Żakowicz, Walecka e Gabińska, 2006) investigou o self dialógico sem recorrer aos instrumentos citados. As autoras buscaram avaliar algumas proposições teóricas sobre o self dialógico, notadamente a de que cada posição do eu produz uma narrativa diferente de si, resultando em que um mesmo indivíduo apresenta diferentes facetas de acordo com a posição do eu que é prevalente (ou seja, que recebe voz) em um dado momento. A tarefa 
utilizada para estudar o fenômeno consistiu, inicialmente, em os participantes serem solicitados a produzir uma narrativa. A instrução para preparar essa narrativa variou em dois aspectos: a pessoa mencionada (mãe, pai, amigo, parceiro e professor) e a recomendação que precedia a tarefa (nenhuma, imaginar a face dessa pessoa ou descrevê-la). Assim, produziram-se 15 grupos de 16 a 20 pessoas que haviam passado por uma das modalidades específicas de instrução e tarefa. Os resultados foram analisados estatisticamente e indicaram que as narrativas diferem substancialmente entre si, em especial quando comparadas às produções referentes a pais e mães. As histórias referentes às mães foram, em geral, mais positivas e otimistas.

\section{CRÍTICAS AO SELF DIALÓGICO}

Um dos aspectos criticados da teoria do self dialógico é a proposição de que um indivíduo pode assumir uma posição autoral com relação a seu próprio repertório de self. Barresi (2002) afirma que essa ideia vai contra os próprios pressupostos da teoria, tomando-se como base a concepção de self de William James. A contradição encontra-se no fato de que não seria possível, em momento algum, escapar da consciência situada do presente para dar voz às posições. O máximo que parece ser possível atingir, segundo Barresi, seria um "ventriloquismo", um esforço para criar uma ilusão de diálogo entre diferentes posições, que não seriam realmente independentes. Ele afirma, porém, que isso pode ser o mais próximo a que se poderia chegar de um verdadeiro diálogo dentro do self. Essa crítica toma uma dimensão ainda maior a partir do momento em que se leva em consideração a noção de metaposição, que implica em um distanciamento das outras posições. A noção de metaposição também contraria a ideia de um self descentralizado, pois localiza a reflexividade em uma instância estática.

Wiley (2006), por sua vez, também apresenta críticas diretas e indiretas ao modelo. Segundo o autor, a tradição de teóricos pragmatistas ${ }^{2}$, como Peirce, Mead e Dewey, pode ser considerada, de forma mais

2 O adjetivo se refere ao Pragmatismo, movimento filosófico surgido nos Estados Unidos por volta de 1870, cuja ideia central consiste na consideração do significado e da verdade de qualquer teoria em relação à sua utilização prática. Trata-se de uma negação da divisão entre conhecimento e ação. Alguns de seus teóricos mais conhecidos são Charles Sanders Peirce, George Herbert Mead e John Dewey. ampla, como uma teoria de um self dialógico. A ênfase no discurso interno (inner speech, no original) enquanto uma função evolutiva que substitui a estratégia de tentativa e erro seria, nesse caso, o elemento comum em torno do qual o self existiria para os diferentes autores dessa corrente filosófica. Wiley vai mais longe e iguala self dialógico e inner speech, enfatizando os aspectos conscientes e reflexivos, que são as mais frequentes características do conceito de self em diferentes teorias. Outros teóricos - por exemplo, Lysaker (2006) -, discordam da comparação de Wiley, enfatizando que existem aspectos préreflexivos do pensamento que também fazem parte do self. Um exemplo citado pelo autor é o de uma exnamorada que surge para um indivíduo que se encontra em um contexto de trabalho. A ativação de diferentes posições pode levá-lo a uma série de reações, como, por exemplo, dar um abraço ou um aperto de mão, a partir de pensamentos como "quero reatar nosso namoro" ou "tenho que manter uma postura profissional". Segundo Lysaker, estas reações surgiriam de forma difusa, sem uma fonte definida, e qualquer consciência que se pudesse ter de sua emergência seria secundária na decisão sobre que rumo tomar. A grande questão, aqui, parece ser se a definição de self deve ou não ser restrita a processos reflexivos - portanto, conscientes. Trata-se da distinção conceitual em que o uso de uma palavra (self) não implica identidade entre os conceitos nomeados por ela.

A opção por um self que englobe aspectos conscientes e inconscientes, reflexivos e préreflexivos, vai ao encontro das concepções propostas por Damásio (2000) de self autobiográfico e protosself, mas o paralelo não é plenamente concretizado. A posição de Damásio aproxima-se de uma distinção entre cognição (self autobiográfico) e sensação (protosself). Por outro lado, Lysaker (2006) refere-se à reflexividade e pré-reflexividade. Pode-se dizer que o processo de formação e manutenção do protosself é pré-reflexivo, mas os processos préreflexivos citados por Lysaker envolvem muito mais do que o protosself pode produzir em termos de complexidade cognitiva. É possível, portanto, entender os conceitos como parcialmente interligados, numa relação de complementaridade.

O RPP, embora bastante elogiado (Barresi, 2002; DeSouza, 2005; Gonçalves \& Salgado, 2001), apresenta alguns pressupostos problemáticos. Gonçalves e Salgado (2001) alegam que quando o indivíduo responde ao instrumento ele se coloca em uma metaposição, ou seja, consegue fornecer resultados que, aparentemente, não são enviesados por 
nenhuma das posições de seu self. Outro problema é assumir que as relações entre as posições são transsituacionais. Os autores argumentam que duas posições podem ter relações até opostas, dependendo da situação em que o indivíduo se encontre. Além disso, chamam atenção para o fato de que talvez os diálogos internos durante a aplicação do instrumento constituam-se em um dado importante deixado de lado. DeSouza (2005), em um estudo empírico com 17 participantes, utilizou o RPP para averiguar a correspondência entre o conceito de self dialógico e o instrumento. Sua conclusão foi que, embora consiga captar um retrato do self dialógico, o RPP não consegue demonstrar o movimento dialógico de forma eficaz.

\section{CONCLUSÃO}

Muitas das proposições do self dialógico ainda precisam ser refinadas e transformadas em hipóteses testáveis. As aplicações ainda se encontram em estado embrionário. A teoria enfoca a estruturação da mente humana a partir das relações entre seus componentes, e não de sua natureza. $\mathrm{O}$ destaque dado à multiplicidade de posições internas reflete uma preocupação em fugir das simplificações e centralizações recorrentes nas teorias do self. Como um contexto teórico amplo, ela oferece um campo fértil para a interface com outras teorias de áreas afins. Isso decorre, principalmente, de seu estado ainda inicial, em que muitos aspectos não se encontram desenvolvidos, e de sua natureza sistêmica e descentralizada.

Muitas das posições de Hermans, Kempen e Van Loon (1992) se encontram em consonância com diversas perspectivas contemporâneas do pensamento científico. A busca pelo entendimento do funcionamento de sistemas descentralizados perpassa os campos da informática (Johnson, 2000) e da neurociência (Crick \& Cock, 2003). A informática vem cada vez mais lidando com sistemas bottom-up descentralizados, em que componentes cuja complexidade é uma pequena fração daquela do todo de que fazem parte reagem de forma mais efetiva $e$ mais rápida. A neurociência teoriza o cérebro como um sistema composto de neurônios que competem entre si, realizando sinapses que fortalecem algumas relações entre as partes enquanto enfraquecem outras. O resultado da interação caótica entre estas partes dá forma ao cérebro sem que haja alguma região deste que "coordene" o processo. Especial ênfase deve ser dada ao conceito de fenômenos emergentes (Johnson,
2000; Varela, Thompson \& Rosch, 1991), que descreve essa tendência descentralizadora e concebe sistemas que funcionam sem função executiva. Valsiner (2002) trouxe esse conceito de forma geral, mas até o momento nenhum teórico elaborou de forma detalhada a interface entre o self e esses outros sistemas descentralizados.

Em retrospecto, a teoria do self dialógico encontra-se em seu início, e se apresenta como um campo fértil para o desenvolvimento de pesquisas. Refinamentos teóricos são necessários, devidamente amparados em estudos empíricos com variação metodológica adequada. $\mathrm{O}$ engajamento de pesquisadores nessas tarefas em um futuro próximo indicará os rumos da teoria no contexto mais amplo da Psicologia.

\section{REFERÊNCIAS}

Bakhtin, M. (1984). Problems of Dostoevsky's poetics (C. Emerson, Ed. \& Trans.). Minneapolis: University of Minnesota Press. (Original publicado em russo, 1963).

Beebe, J. (2002). An archetypal model of the self in dialogue. Theory \& Psychology, 12, 267-280.

Barresi, J. (2002). From 'the thought is the thinker' to 'the voice is the speaker'. Theory \& Psychology, 12, 237-250.

Branco, A. U. (2005). Peer interaction, language development and metacommunication. Culture \& Psychology, 11(4), 415-429.

Crick, F. \& Cock, C. (2003). A framework for consciousness. Nature Neuroscience, 6, 119-126.

Damásio, A. R. (2000). O mistério da consciência (L. T. Motta, Trad.). São Paulo: Companhia das Letras. (Original publicado em inglês, 1999).

DeSouza, M. L. (2005). Self semiótico e self dialógico: Uma investigação da reflexividade da consciência. Tese de Doutorado não publicada. Curso de Pós-Graduação em Psicologia, Universidade Federal do Rio Grande do Sul. Porto Alegre, RS.

Fogel, A., Koeyer I., Bellagamba F. \& Bell, H. (2002). The dialogical self in the first two years of life. Theory and Psychology, 12, 191205.

Gonçalves, M. M., \& Salgado, J. (2001). Mapping the multiplicity of the self. Culture \& Psychology, 7, 367-377.

Hermans, H. J. M. (2001a). The dialogical self: Toward a theory of personal and cultural positioning. Culture \& Psychology, 7, 243281.

Hermans, H. J. M. (2001b). The construction of a personal position repertoire: Method and practice. Culture \& Psychology, 7, 323365.

Hermans, H. J. M. (2002). The dialogical self as a society of mind. Theory \& Psychology, 12, 147-160.

Hermans, H. J. M. (2003). The construction and reconstruction of a dialogical self. Journal of Constructivist Psychology, $16,89-130$. 
Hermans, H. J. M., \& Kempen, H. J. G. (1998). Moving cultures: The perilous problems of cultural dichotomies in a globalizing society. American Psychologist, 53, 1111-1120.

Hermans, H. J. M., Kempen, H. J. G. \& Van Loon, R. J. P. (1992). The dialogical self: beyond individualism and rationalism. American Psychologist, 47, 23-33.

James, W. (2007). The principles of psychology Vol. I. NY: Cosimo Classics. (Original publicado em 1890).

Johnson, S. (2000). Emergência. Rio de Janeiro: Jorge Zahar Ed.

Leiman, M. (2002). Toward semiotic dialogism: The role of sign mediation in the dialogical self. Theory \& Psychology, 12, 221235.

Lewis, M. D. (2002). The dialogical brain. Theory \& Psychology, 12, 175-190.

Lysaker, P. H. \& Lysaker, J. T. (2002). Narrative structure in psychosis: schizophrenia and disruptions of the dialogical self. Theory \& Psychology, 12, 207-220.

Lysaker, J. T. (2006). "I am not what I seem to be". International Journal for Dialogical Science, 1, 43-45.

Lysaker, P. H. \& Hermans, H. J. M. (2007). The dialogical self in psychotherapy for persons with schizophrenia: A case study. Journal of Clinical Psychology, 63(2), 129-139.

Oliveira, M. C. L. S. (2006). Identidade, narrativa e desenvolvimento na adolescência: Uma revisão crítica. Psicologia em Estudo, 11(2), 427-436.
Raggat, P. T. F. (2000). Mapping the dialogical self: Towards a rationale and method of assessment. European Journal of Personality, 14, 65-90.

Santos, M. A. (2007). Movimentos dialógicos do self em psicoterapia. Dissertação de mestrado não publicada. Curso de Pós-Graduação em Psicologia, Universidade Federal do Rio Grande do Sul. Porto Alegre, RS.

Stemplewska-Żakowicz, K., Walecka, J. \& Gabińska, A. (2006). As many selves as interpersonal relations (maybe even more). International Journal for Dialogical Science, 1, 71-94.

Valsiner, J. (2002). Forms of dialogical relations and semiotic autoregulation within the self. Theory \& Psychology, 12, 251-265.

Varela, F. J., Thompson, E., \& Rosch, E. (1991). The Embodied Mind. Cambrige, MA: MIT Pres.

Wiley, N. (1994). The semiotic self. Chicago: The Univ. Chicago Press

Wiley, N. (2006). Pragmatism and the dialogical self. International Journal for Dialogical Science, 1, 5-21.

Recebido em 09/06/2008

Aceito em 15/12/2009

\section{Endereço para correspondência:}

William B. Gomes. Rua Couto de Magalhães 1155/601, CEP 90540-131, Porto Alegre-RS, Brasil.E-mail: gomesw@ufrgs.br. 